\title{
The Mechanism of Cornus officinalis Total Glycosides and Cornus Polysaccharide on Myocardial Protection in Rats with Acute Myocardial Infarction
}

\author{
Ke Chen, Jianjun $\mathrm{Li}^{*}$, Kefang Chen, Xiangping Hou, Huachao Mai, Xiaojin Xue \\ Department of Traditional Chinese Medicine, Sun Yat-sen Memorial Hospital Affiliated to \\ Sun Yat-sen University, Guangzhou, China \\ Email: 'Lij1965wuan@126.com
}

Received 6 May 2016; accepted 4 June 2016; published 7 June 2016

Copyright (C) 2016 by authors and Scientific Research Publishing Inc.

This work is licensed under the Creative Commons Attribution International License (CC BY). http://creativecommons.org/licenses/by/4.0/

(c) (i) Open Access

\begin{abstract}
Objective: To investigate effects of Cornus officinalis Total Glycosides (COTG) and Cornus Polysaccharide (CP) on myocardial protection and on expression of mitochondria biogenesis related gene of acute myocardial infarction (AMI) rats, Materials and Methods: Ninety-six SD rats of SPF level were randomly divided into 5 groups: sham operation group, model group, preventive treatment group, COTG treatment group, CP treatment group, and there were 12 cases in each one. By legating the left anterior descending branch of coronary artery method, acute myocardial infarction model was established. The rat of sham operation group and model group was intragastric administered with physiological saline; other groups were given with corresponding drugs. The cardiac function, the myocardial infarct area, the expression of mitochondrial biogenesis genes such as PGC-1 $\alpha$, PGC-1 $\beta$, NRF-1mRNA and GSK-3 $\beta$ mRNA, GSK-3 $\beta$ Protein Expression were analyzed. Results: The results revealed that compared with model group, myocardial infarction size, LVDs, LVDd, LVESV, LVEDP, and -dp/dt decreased; LVSP increased in preventive treatment group, COTG treatment group, and CP treatment group ( $p<0.05)$; LVEDV increased in preventive treatment group ( $<$ 0.05), PGC 1 alpha, and PGC 1 beta; the NRF-1 mRNA expression increased in preventive treatment group, COTG treatment group, and CP treatment group $(\mathrm{p}<0.05)$. Compared with $\mathrm{CP}$ and COTG treatment group, PGClpha, beta PGC 1, the NRF-1 mRNA expression increased in preventive treatment group $(p<0.05)$. Compared with the sham operation group, GSK-3 beta mRNA and protein expression increased in model group, preventive treatment group, COTG treatment group, and CP treatment group $(\mathrm{p}<0.05)$. Compared with model group, GSK-3 beta mRNA expression reduced in preventive treatment group, COTG treatment group, and CP treatment group ( $p<$ 0.05). Conclusions: Cornus officinalis total glycosides and Cornus polysaccharides can effectively

"Corresponding author.
\end{abstract}

How to cite this paper: Chen, K., Li, J.J., Chen, K.F., Hou, X.P., Mai, H.C. and Xue, X.J. (2016) The Mechanism of Cornus officinalis Total Glycosides and Cornus Polysaccharide on Myocardial Protection in Rats with Acute Myocardial Infarction. Chinese Medicine, 7, 45-54. http://dx.doi.org/10.4236/cm.2016.72007 
protect myocardial mitochondria of acute myocardial infarction rats by activating GSK- $3 \beta$ signaling pathways, and reduce the myocardial infarct size, which has great significance for improving cardiac function.

\section{Keywords}

\section{Cornus officinalis Total Glycosides, Cornus Polysaccharide, Acute Myocardial Infarction, Glycogen Synthase Kinase 3 Beta}

\section{Introduction}

Currently in the clinics, acute myocardial infarction (AMI) is a still problem awaiting the settlement. It has been demonstrated that the traditional Chinese medicine of Cornus officinalis maintains anti-inflammatory function, has remarkable antioxidant activity and can inhibit myocardial hypertrophy. Specifically, it is propitious to protect the rat from myocardial injury [1], lessen myocardial hypertrophy caused by renovascular hypertension [2] and protect the cardiovascular of diabetic cardiomyopathy rats [3]. However, the protective mechanism of Cornus officinalis on myocardial mitochondria in rats with acute myocardial infarction is rarely reported. As all we know that glycogen synthase kinase-3 beta (GSK-3 $\beta$ ) is a multifunctional serine/threonine protein kinase. Recent discoveries indicated that GSK-3 $\beta$ is closely interrelated with angiocardiopathy, such as myocardial ischemia reperfusion injury [4], myocardial hypertrophy [5], cardiomyocyte apoptosis [6], the occurrence and development of atherosclerosis [7], the inflammatory response after myocardial infarction [8], heart failure [9], etc. Although there have been many studies on GSK-3 $\beta$, it is unclear whether Cornus officinalis total glycosides and Cornus polysaccharides can protect myocardial mitochondria of acute myocardial infarction rats and whether protective effects could be achieved by GSK- $3 \beta$ signaling pathways. The aim of the present study was to explore the mechanism of mitochondrial protection of Cornus officinalis Sieb. et Zucc on acute myocardial infarction in rats. Additionally, the study explored whether GSK-3 $\beta$ signaling was involved in improving cardiac function.

\section{Materials and Methods}

\subsection{Reagents and Drug}

Cornus medicinal materials were provided by Guangdong E-FONG pharmaceutical Co. Ltd. Extraction and determination of Cornus officinalis total glycosides and Cornus polysaccharides from Cornus officinalis Sieb. et Zucc were completed by Professor Dongmei Sun [10] [11].

Main reagents: Trizol (Invitrogen Batch No. 1373341); SuperScript III Reverse Transcriptase SYBR ${ }^{\mathrm{R}} \mathrm{RT}-\mathrm{PCR}$ Kit (Invitrogen Batch No. 18064014); Quantitative PCR Kit (Ta Ka Ra No. BK8803); BCA-100 Protein kit (Shanghai Shenergy Biotechnology Co. Ltd. No. K3000); Trisbase (Guangzhou Kanglong Biotechnology Co. Ltd. No. 2008616); 30\% acrylamide/0.8\% N N-methylene acrylamide (Shanghai Shenergy Biotechnology Co. Ltd. No. 091001); SDS sample loading buffer (Ta Ka Ra No. D606); Tween-20 (Guangzhou RayBiotech Co. Ltd. No. 20090510); Ammonium Persulfate (APS, Guangzhou RayBiotech Co. Ltd. No. 20100420); N,N,N',N'tetramethylethylenediamine (TEMED, Sigma, No. T8133); $\beta$-action (Boster Biological Technology Co. Ltd. No. ba637); Second Antibody (Invitrogen No. SC465); Chemiluminescent substrate solution kit (Invitrogen No. 20090813); Developing fixer Kit (Beyotime Institute of Biotechnology No. 080310); Methanol (Shantou Xilong Chemical Factory No. 080814); Chloroform (Guangzhou Ray Biotech Co. Ltd. No. 090504); Isopropanol (Guangzhou Ray Biotech Co. Ltd. No. 091012); 75\% Alcohol (Guangzhou Ray Biotech Co. Ltd. No. 080918); Glycine (Guangzhou Kanglong Biotechnology Co. Ltd. No. 081107); 10\% Chloral Hydrate (Sinopharm Chemical Reagent Co., Ltd. No. 090310); 4\% Para Formaldehyde (Guangzhou Ray Biotech Co. Ltd. No. 20090922); Phosphate Buffer Solution (BioBasiclnc Canada No. 0910P06); Neutral Balsam (Guangzhou Ray Biotech Co. Ltd. No. 20090418).

\subsection{Animals}

96 of male Sprague-Dawley rats of SPF level, weighing 200 - 250 g, were provided by the Animal Experimental 
Center of Southern Medical University (number of animal license SCXK 2006-0015). The experimental AMI model was induced by the ligation of the left anterior descending branch of coronary artery in $60 \mathrm{SD}$ rats, as previously described [12] [13]. After 24 hours of operation, the 38 rats survived were randomly divided into three groups, including model of AMI group $(n=12)$, COTG treatment group $(n=13)$, CP treatment group $(n=$ 13). The other 36 rats were randomly divided into sham operation group $(\mathrm{n}=12)$ and preventive treatment group $(n=24), 15$ of which survived after occlusion of the left anterior descending coronaryartery. Among the 15 rats 3 died after intragastric administration, namely, there were 12 rats in preventive treatment group. Reference to the existing research [14], experimental rats were given with $12 \mathrm{~g} / \mathrm{kg}$ Cornus officinalis of crude drug, whose dose equivalent to 20 times clinical adult dosage.

According to the extraction rate to determine the dose of COTG and CP. In sham operation group and AMI model group, rats were administered by intragastric with physiological saline in the preoperative and postoperative 7 days. In the preventive treatment group, rats were given Cornus officinalis Total Glycosides before the operation for 7 days and were given physiological saline after a week. Rats in COTG treatment group and CP treatment group were given intragastric administration of physiologic saline in the preoperative 7 days, which were respectively administered with Cornus officinalis Total Glycosides and Cornus Polysaccharide in the postoperative 7 days.

\subsection{Echocardiography Examination}

On the fifteenth days, 6 rats in each group underwent echocardiographic examination after intraperitoneal injection anesthesia, including interventricular septum systolic thickness (IVSs), interventricularseptal diastolic thickness (IVSd), left ventricular posterior wall systolic thickness (PWs), posterior wall of left ventricular end diastolic thickness (PWd), systolic left ventricular diameter (LVDs), left ventricular diastolic diameter (LVDd), left ventricular end diastolic volume (LVEDv), left ventricular end systolic volume (LVESv), ejection fraction (EF) and fraction shortening (FS).

\subsection{Hemodynamic Detection}

The rats of other 6 rats in each group were anesthetized with 10\% chloral hydrate injecting into the abdominal cavity with a dosage at $35 \mathrm{ml} / \mathrm{kg}$, supine fixed in the operating table, right carotid artery intubation were performed, three-limb tubes, Micro catheter, Pressure sensor and Recorder were connected after calibration, and then parameters of cardiac function were measured by means of multichannel physiologic recorder: aortic systolic pressure (SBP); aortic diastolic pressure (DBP); left ventricular end systolic pressure (LVESP); left ventricular end diastolic pressure (LVEDP); maximal rate of rise of left ventricular pressure (+dp/dt max); maximal rate of decrease of left ventricular pressure ( $-\mathrm{dp} / \mathrm{dt}$ max). All of those indexes reflect left ventricular systolic and diastolic function.

\subsection{HE Staining of Myocardial Tissue}

The 6 rats that had completed the hemodynamic detection were sacrificed, hearts were removed, subsequently, cut out the pieces of 1 or 2 tissue along the largest part of the left ventricular diameter, were immediately fixed in $4 \%$ para formaldehyde for 24 hand dehydrated with ethanol of gradient concentration, then cleared in xylene, finally embedded in paraffin. The tissue blocks were sectioned at 6 um thickness which used for HE stain.

\subsection{Myocardial Infarct Area}

Using Masson staining to detect myocardial infarct area of 6 rats, which had finished echocardiography examination. The details are summarized as follows: Left ventricular tissue were taken for paraffin sections at 3 - 5 um, were dewaxed and washed with distilled water, followed by Masson staining. Microscope digital image analysis system of Image-Pro-Plus 6.0 was applied to analyze the images of the stained myocardial sections.

\subsection{The Expression of Mitochondria Biogenesis Related Gene PGC-1 $\alpha$, PGC-1 $\beta$ and NRF-1}

Real-time fluorescent quantitative PCR method. Specific divided into the following steps: Firstly total RNA was isolated from the rat myocardial tissues using Trizol reagent. $\mathrm{A}_{260}$ and $\mathrm{A}_{280}$ absorption value were determined by 
ultraviolet-visible spectrophotometer, the ratio of them determined the extraction of RNA. Secondly, reverse transcription: 1 ul Random Primer, 2.5 ug RNA and $1 \mathrm{ul} 10 \mathrm{mM}$ dNTP mix, added water to 13 ul, incubation for 5 minutes at $65^{\circ} \mathrm{C}$, ice bath for at least 1 min, 4 ul $5^{*}$ Frist-strand Buffer, 1 ul 0.1 MDTT and 1 ul RNase out ${ }^{\text {TM }}$ Recombinate RNase Inhibitor were added in reaction products above, centrifugal to $5000 \mathrm{~g} / \mathrm{min}$, this was to mix reaction system, annealing at $25^{\circ} \mathrm{C}$ for $5 \mathrm{~min}$, elongation at $50^{\circ} \mathrm{C}$ for $30-60 \mathrm{~min}$, inactivation of reverse transcriptase at $70^{\circ} \mathrm{C}$ for $15 \mathrm{~min}$, total RNA was reverse transcribed into cDNA. Thirdly, real-time fluorescent quantitative PCR: the PCR reaction mix (final volume, $20 \mu \mathrm{l}$ ) consisted of: $10 \mu \mathrm{l}$ SYBY, $0.4 \mu \mathrm{l}$ primer mix, $2 \mu \mathrm{l}$ template and $7.6 \mu \mathrm{l}$ DEPC $\mathrm{H}_{2} \mathrm{O}$. As an internal reference, the expression of beta-action mRNA in each sample was detected at the same time, according to the reaction conditions shown in the Table 1. Each experiment was independently repeated 3 - 5 times. The PCR cycling conditions were as follows: Initial denaturation at $95^{\circ} \mathrm{C}$ for $20 \mathrm{sec}$, followed denaturation at $95^{\circ} \mathrm{C}$ for $10 \mathrm{sec}$, annealing at $60^{\circ} \mathrm{C}$ for $20-60 \mathrm{sec}$, by 38 - 45 cycles of incubation at $70^{\circ} \mathrm{C}$ for $1 \mathrm{sec}$, and solubility curve was drawn at $65^{\circ} \mathrm{C}$ to $95^{\circ} \mathrm{C}$. The final result was copy number, when reached the setting values of $\mathrm{Ct}$. The value of $\mathrm{Ct}$ decreased with increasing template concentration, therefore, the value of $\mathrm{Ct}$, which showed in real-time fluorescent quantitative PCR, have an inverse relationship with the expression level of mRNA.

\subsection{The Expression of GSK-3 $\beta$}

Using real time fluorescence quantitative PCR method, the primer sequences are shown in Table 1.

\subsection{Statistical Methods}

Statistical software package SPSS 13.0 was applied to analyze the data; measurement data are presented as means \pm standard deviation; multiple groups means were compared with single factor analysis of variance; the comparison among groups was performed with LSD-t test; rank-sum test was applied for non-normal distribution of measurement data; $\mathrm{p}<0.05$ was considered with statistical significance.

\section{Results}

\subsection{Comparisons of Echocardiography in Five Group (Table 2)}

The results indicated that EF and FS were significantly decreased, while LVDs, LVDd, LVESV and LVEDV were significantly increased, in model group compared with sham operation group $(\mathrm{p}<0.05)$. Compared with model group, LVDs, LVDd and LVEDV were significantly decreased in preventive treatment group, COTG treatment group and CP treatment group, EF and FS were significantly increased, by contrast, LVESV were significantly decreased in preventive treatment group $(\mathrm{p}<0.05)$. Compared with preventive treatment group, in COTG treatment group were significantly increased, EF in CP treatment group were significantly decreased ( $\mathrm{p}<$ 0.05). EF and FS were significantly decreased in CP treatment group when compared with COTG treatment group $(\mathrm{p}<0.05)$.

\begin{tabular}{|c|c|c|}
\hline Gene & Primer sequences & Length (bp) \\
\hline \multirow{3}{*}{ PGC- $1 \alpha$} & Forward 5‘-ATG CAC TGA CAG ATG GAG ACG TGAC-3’ & \multirow{3}{*}{220} \\
\hline & & \\
\hline & Reverse 5‘-GTT CCT ATA CCA TAG TCA TGC ATTG-3’ & \\
\hline \multirow{2}{*}{ PGC- $1 \beta$} & Forward 5‘-ACTA TGA TCC CAC GTC TGA AGA GTC-3’ & \multirow{2}{*}{152} \\
\hline & Reverse 5‘-CCT TGT CTG AGG TAT TGA GGT ATTC-3’ & \\
\hline \multirow{2}{*}{ NRF-1 } & Forward 5‘-TTA CTC TGC TGT GGC TGA TGG-3’ & \multirow{2}{*}{92} \\
\hline & Reverse 5‘-CCT CTG ATG CTT GCG TCG TCT-3’ & \\
\hline \multirow{2}{*}{ GSK-3 $\beta$} & Forward 5‘-CCT TAA CCT GGT GCT GGA CT-3’ & \multirow{2}{*}{300} \\
\hline & Reverse 5‘-AGC TCT GGT GCC CTG TAG TA-3’ & \\
\hline
\end{tabular}




\subsection{Comparisons of Hemodynamic Results in Five Group (Table 3)}

Compared with sham group, HR, LVESP, SBP, dp dt max and -dp/dt max were significantly decreased in model group, LVEDP and DBP were significantly increased ( $\mathrm{p}<0.05$ ). Compared with model group, preventive treatment group, COTG treatment group and CP treatment group, in which LVESP, SBP and - dp/dt max were significantly increased, LVEDP and DBP were significantly decreased $(\mathrm{p}<0.05)$. Compared with preventive treatment group, SBP in COTG treatment group were significantly increased $(\mathrm{p}<0.05)$. Compared with COTG treatment group, LVESP and SBP were significantly decreased $(\mathrm{p}<0.05)$.

\subsection{Comparison on Pathological Results of Cardiac Tissue in Rats (Figure 1)}

After the HE staining, the structures of normal myocardium were seen clearly, with blue nucleus, bright red cell cytoplasm, various red in connective tissue, erythrocyte and eosinophilic granules, and blue or purple-blue calcium salt and microorganisms. In infarct zone of model group, the positive dyeing intensity of myocardial tissue was evidently weakened, the amount of myocardial cells was greatly decreased, sarcoplasm of myocardial fibers was dissolved, the transverse striation disappeared, fibroblast proliferation, collagen deposition, nuclear condensation or fragmentation and leukocyte infiltration. Compared with model group, the degree of myocardial

Table 2. The results of echocardiography in five groups.

\begin{tabular}{cccccc}
\hline Group & $\begin{array}{c}\text { Sham } \\
(\mathrm{n}=6)\end{array}$ & $\begin{array}{c}\text { Model } \\
(\mathrm{n}=6)\end{array}$ & $\begin{array}{c}\text { Prevention } \\
(\mathrm{n}=6)\end{array}$ & $\begin{array}{c}\text { Cornus officinalis } \\
\text { Total Glycosides } \\
(\mathrm{n}=6)\end{array}$ & $\begin{array}{c}\text { Cornus } \\
\text { polysaccharides } \\
(\mathrm{n}=6)\end{array}$ \\
\hline IVSs & $2.56 \pm 0.38$ & $2.83 \pm 0.20$ & $2.52 \pm 0.26$ & $2.77 \pm 0.17$ & $2.64 \pm 0.26$ \\
IVSd & $1.48 \pm 0.15$ & $1.45 \pm 0.12$ & $1.45 \pm 0.07$ & $1.50 \pm 0.09$ & $1.39 \pm 0.12$ \\
PWs & $2.73 \pm 0.25$ & $2.76 \pm 0.12$ & $2.72 \pm 0.19$ & $2.69 \pm 0.16$ & $2.70 \pm 0.18$ \\
PWd & $1.42 \pm 0.15$ & $1.40 \pm 0.15$ & $1.39 \pm 0.10$ & $1.46 \pm 0.11$ & $1.40 \pm 0.09$ \\
LVDs & $3.02 \pm 0.27$ & $5.66 \pm 0.27^{\mathrm{a}}$ & $4.74 \pm 0.30^{\mathrm{ab}}$ & $5.00 \pm 0.17^{\mathrm{ab}}$ & $4.94 \pm 0.16^{\mathrm{ab}}$ \\
LVDd & $5.55 \pm 0.17$ & $6.74 \pm 0.20^{\mathrm{a}}$ & $5.97 \pm 0.11^{\mathrm{ab}}$ & $5.91 \pm 0.18^{\mathrm{ab}}$ & $6.04 \pm 0.14^{\mathrm{ab}}$ \\
LVESV & $0.05 \pm 0.17$ & $0.19 \pm 0.03^{\mathrm{a}}$ & $0.14 \pm 0.03^{\mathrm{ab}}$ & $0.16 \pm 0.03^{\mathrm{a}}$ & $0.17 \pm 0.05^{\mathrm{a}}$ \\
LVEDV & $0.30 \pm 0.04$ & $0.60 \pm 0.04^{\mathrm{a}}$ & $0.46 \pm 0.05^{\mathrm{ab}}$ & $0.48 \pm 0.05^{\mathrm{ab}}$ & $0.45 \pm 0.03^{\mathrm{ab}}$ \\
FS & $58.80 \pm 1.41$ & $21.33 \pm 1.93^{\mathrm{a}}$ & $41.48 \pm 1.40^{\mathrm{ab}}$ & $52.72 \pm 3.08^{\mathrm{abc}}$ & $42.68 \pm 3.30^{\mathrm{abd}}$ \\
EF & $91.88 \pm 1.02$ & $63.42 \pm 4.40^{\mathrm{a}}$ & $84.75 \pm 4.78^{\mathrm{ab}}$ & $82.23 \pm 3.86^{\mathrm{ab}}$ & $73.97 \pm 3.45^{\mathrm{abcd}}$ \\
\hline
\end{tabular}

${ }^{a} \mathrm{p}<0.05$ vs. sham group; ${ }^{b} \mathrm{p}<0.05$ vs. model of AMI group; ${ }^{\mathrm{c}} \mathrm{p}<0.05$ vs. preventive treatment group; ${ }^{\mathrm{d}} \mathrm{p}<0.05$ vs. COTG treatment group.

Table 3. The hemodynamic results of rats in five groups.

\begin{tabular}{|c|c|c|c|c|c|}
\hline Group & $\begin{array}{l}\text { Sham } \\
(n=6)\end{array}$ & $\begin{array}{l}\text { Model } \\
(n=6)\end{array}$ & $\begin{array}{c}\text { Prevention } \\
\quad(n=6)\end{array}$ & $\begin{array}{l}\text { Cornus officinalis } \\
\text { Total Glycosides } \\
\qquad(\mathrm{n}=6)\end{array}$ & $\begin{array}{l}\text { Cornus } \\
\text { polysaccharides } \\
(n=6)\end{array}$ \\
\hline $\mathrm{HR}$ & $524.00 \pm 16.00$ & $481.00 \pm 22.00^{\mathrm{a}}$ & $467.00 \pm 30.00^{\mathrm{a}}$ & $456.00 \pm 19.00^{\mathrm{a}}$ & $461.00 \pm 16.00^{\circ}$ \\
\hline LVSP (mmHg) & $124.51 \pm 4.66$ & $80.94 \pm 6.51^{a}$ & $97.10 \pm 5.35^{\mathrm{ab}}$ & $99.47 \pm 3.59^{\mathrm{ab}}$ & $92.85 \pm 1.56^{\mathrm{abc}}$ \\
\hline LVEDP (mmHg) & $2.98 \pm 0.48$ & $23.50 \pm 3.29^{\mathrm{a}}$ & $14.95 \pm 1.83^{\mathrm{ab}}$ & $15.63 \pm 1.76^{\mathrm{ab}}$ & $16.03 \pm 2.08^{\mathrm{ab}}$ \\
\hline SBP (mmHg) & $113.73 \pm 3.56$ & $79.68 \pm 5.28^{\mathrm{a}}$ & $92.75 \pm 3.35^{\mathrm{ab}}$ & $98.01 \pm 3.47^{\mathrm{abc}}$ & $89.83 \pm 1.63^{\mathrm{abd}}$ \\
\hline DBP (mmHg) & $67.89 \pm 5.20$ & $93.19 \pm 3.62^{\mathrm{a}}$ & $70.92 \pm 3.77^{\mathrm{a}}$ & $70.34 \pm 2.95^{b}$ & $68.22 \pm 2.22^{\mathrm{b}}$ \\
\hline$+\mathrm{dp} / \mathrm{dt}(\mathrm{mmHg} / \mathrm{ms})$ & $6.39 \pm 1.06$ & $4.53 \pm 0.33^{\mathrm{a}}$ & $4.39 \pm 0.20^{\mathrm{a}}$ & $4.77 \pm 0.25^{\mathrm{a}}$ & $4.32 \pm 0.26^{\mathrm{a}}$ \\
\hline$-\mathrm{dp} / \mathrm{dt}(\mathrm{mmHg} / \mathrm{ms})$ & $7.26 \pm 0.27$ & $4.59 \pm 0.22^{\mathrm{a}}$ & $5.58 \pm 0.50^{\mathrm{ab}}$ & $5.30 \pm 0.17^{\mathrm{ab}}$ & $5.45 \pm 0.16^{\mathrm{ab}}$ \\
\hline
\end{tabular}

${ }^{\mathrm{a}} \mathrm{p}<0.05$ vs. sham group; ${ }^{\mathrm{b}} \mathrm{p}<0.05$ vs. model of AMI group; ${ }^{\mathrm{c}} \mathrm{p}<0.05$ vs. preventive treatment group; ${ }^{\mathrm{d}} \mathrm{p}<0.05$ vs. COTG treatment group. 


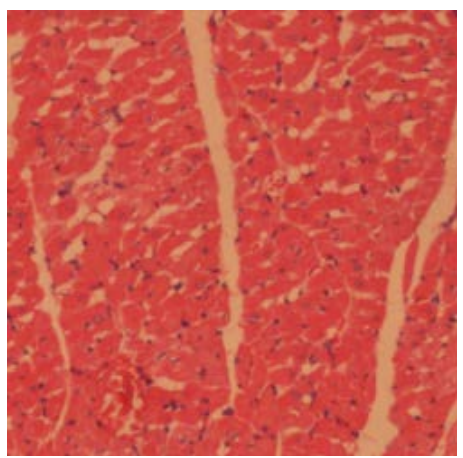

(a)

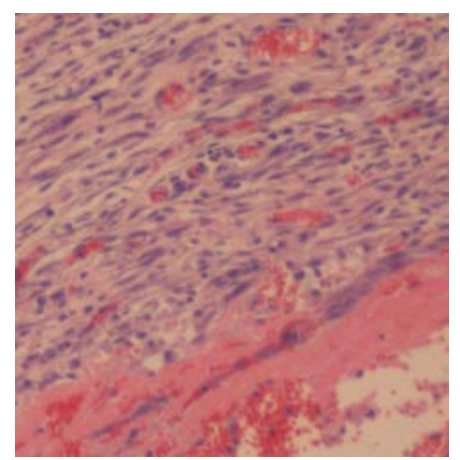

(b)

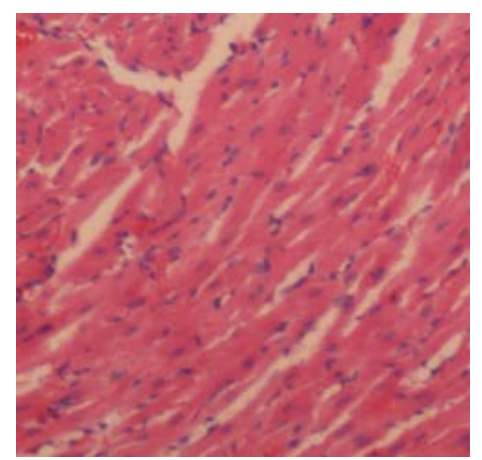

(c)

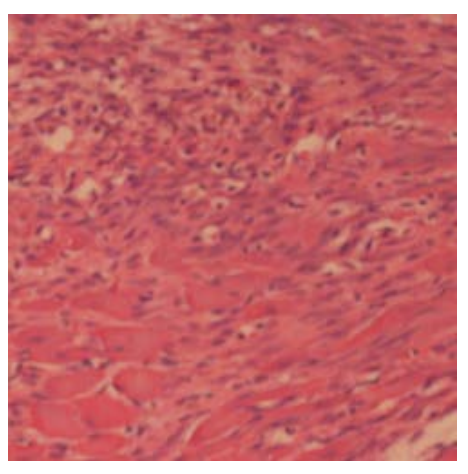

(d)

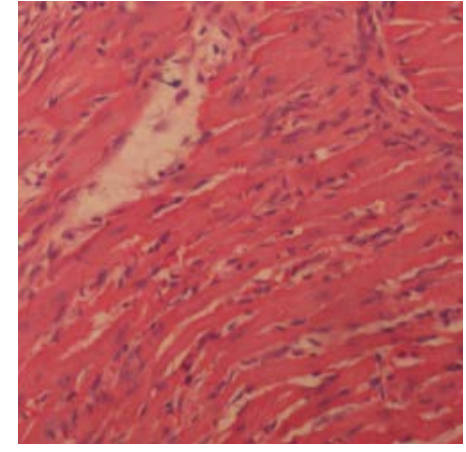

(e)

Figure 1. The pathological results of cardiac tissue in five groups (HE). (a) Sham group; (b) Model group; (c) Preventive group; (d) COTG group; (e) CP group.

damage was evidently reduced, the number of myocardial cells was increased, fibroblasts were slightly proliferated, the number of white blood cell was reduced.

\subsection{Comparisons of Myocardial Infarct Area in Rat (Table 4)}

Cardiac weight, the heart to body weight ratio, the left ventricular mass and the infarct area in model group were significantly higher than that in sham operation group $(\mathrm{p}<0.05)$. Compared with model group, the left ventricular mass and the infarct area were significantly decreased in preventive treatment group, COTG treatment group and CP treatment group; the cardiac weight was significantly decreased in COTG treatment group and CP treatment group; the heart to body weight ratio was significantly decreased in CP treatment group $(\mathrm{p}<0.05)$. Compared with preventive treatment group, the cardiac weight was significantly decreased in COTG treatment group and CP treatment group ( $\mathrm{p}<0.05)$.

\subsection{Comparisons on the Ct Value of Mitochondria Biogenesis Gene Such as NRF-1, PGC-1A and PGC-1B in Five Groups (Table 5)}

Compared with sham operation group, the Ct value of NRF-1, PGC- $1 \alpha$ and PGC- $1 \beta$ were significantly increased in model group $(\mathrm{p}<0.05)$. Compared with model group, the Ct value of NRF-1 were significantly decreased in preventive treatment group, COTG treatment group and CP treatment group ( $<<0.05)$, the Ct value of PGC-1 $\alpha$ and PGC- $1 \beta$ were significantly decreased in preventive treatment group and CP treatment group $(\mathrm{p}<0.05)$. Compared with preventive treatment group, the Ct value of NRF-1, PGC- $1 \alpha$ and PGC- $1 \beta$ were significantly increased in COTG treatment group and CP treatment group $(\mathrm{p}<0.05)$.

\subsection{Comparisons on the Ct Value of GSK-3 $\beta$ in Myocardial Tissue of Rats}

Compared with sham operation group, the Ct value of GSK-3 $\beta$ was significantly decreased in model group ( $\mathrm{p}<$ 0.05). Compared with model group, the Ct value of GSK-3 $\beta$ in CP treatment group was significantly increased 
Table 4. The myocardial infarct area in five groups.

\begin{tabular}{cccccc}
\hline Group & $\begin{array}{c}\text { Sham } \\
(\mathrm{n}=12)\end{array}$ & $\begin{array}{c}\text { Model } \\
(\mathrm{n}=12)\end{array}$ & $\begin{array}{c}\text { Prevention } \\
(\mathrm{n}=12)\end{array}$ & $\begin{array}{c}\text { Cornus officinalis } \\
\text { Total Glysides } \\
(\mathrm{n}=12)\end{array}$ & $\begin{array}{c}\text { Cornus } \\
\text { polysachrides } \\
(\mathrm{n}=12)\end{array}$ \\
\hline $\begin{array}{c}\text { Preoperative } \\
\text { bodyweight (g) } \\
\begin{array}{c}\text { Postoperative } \\
\text { bodyweight (g) }\end{array}\end{array}$ & $207.50 \pm 7.23$ & $204.50 \pm 7.62$ & $205.42 \pm 7.82$ & $203.75 \pm 7.42$ & $204.17 \pm 7.64$ \\
$\begin{array}{c}\text { Cardiac } \\
\text { weight (mg) }\end{array}$ & $678.00 \pm 12.12$ & $703.20 \pm 11.60^{\mathrm{a}}$ & $696.67 \pm 7.68^{\mathrm{a}}$ & $686.42 \pm 3.90^{\mathrm{abc}}$ & $688.14 \pm 6.43^{\mathrm{abc}}$ \\
$\begin{array}{c}\text { Heart to body } \\
\text { weight ratio }\end{array}$ & $2.90 \pm 0.03$ & $3.03 \pm 0.07^{\mathrm{a}}$ & $2.99 \pm 0.06^{\mathrm{a}}$ & $2.99 \pm 0.07^{\mathrm{a}}$ & $2.97 \pm 0.07^{\mathrm{ab}}$ \\
$\begin{array}{c}\text { Left ventricular } \\
\text { mass (mg) }\end{array}$ & $537.17 \pm 9.89$ & $600.30 \pm 19.67^{\mathrm{a}}$ & $565.67 \pm 10.23^{\mathrm{ab}}$ & $565.00 \pm 9.40^{\mathrm{ab}}$ & $572.75 \pm 8.09^{\mathrm{ab}}$ \\
$\begin{array}{c}\text { Infarct area } \% \\
(\mathrm{n}=6)\end{array}$ & $1.20 \pm 1.02$ & $34.50 \pm 5.06^{\mathrm{a}}$ & $28.72 \pm 2.36^{\mathrm{ab}}$ & $26.58 \pm 1.78^{\mathrm{ab}}$ & $26.18 \pm 1.38^{\mathrm{ab}}$ \\
\hline
\end{tabular}

${ }^{\mathrm{a}} \mathrm{p}<0.05$ vs. sham group; ${ }^{\mathrm{b}} \mathrm{p}<0.05$ vs. model of AMI group; ${ }^{\mathrm{c}} \mathrm{p}<0.05$ vs. preventive treatment group; ${ }^{\mathrm{d}} \mathrm{p}<0.05$ vs. COTG treatment group.

Table 5. The Ct value of NRF-1, PGC-1 $\alpha$ and PGC-1 $\beta$ in mitochondria biogenesis gene of five groups.

\begin{tabular}{cccccc}
\hline Group & $\begin{array}{c}\text { Sham } \\
(\mathrm{n}=10)\end{array}$ & $\begin{array}{c}\text { Model } \\
(\mathrm{n}=10)\end{array}$ & $\begin{array}{c}\text { Prevention } \\
(\mathrm{n}=10)\end{array}$ & $\begin{array}{c}\text { Cornus officinalis } \\
\text { Total Glycosides } \\
(\mathrm{n}=10)\end{array}$ & $\begin{array}{c}\text { Cornus } \\
\text { polysaccharides } \\
(\mathrm{n}=10)\end{array}$ \\
\hline NRF-1 & $8.04 \pm 0.47$ & $9.08 \pm 0.67^{\mathrm{a}}$ & $6.13 \pm 0.88^{\mathrm{ab}}$ & $7.31 \pm 0.48^{\mathrm{abc}}$ & $7.56 \pm 0.44^{\mathrm{abc}}$ \\
PGC-1 $\alpha$ & $6.45 \pm 1.14$ & $9.15 \pm 0.91^{\mathrm{a}}$ & $5.95 \pm 0.91^{\mathrm{ab}}$ & $8.46 \pm 1.09^{\mathrm{ac}}$ & $7.74 \pm 1.17^{\mathrm{abc}}$ \\
PGC-1 $\beta$ & $5.30 \pm 0.99$ & $7.06 \pm 0.61^{\mathrm{ab}}$ & $4.26 \pm 0.64^{\mathrm{ab}}$ & $6.67 \pm 0.80^{\mathrm{ac}}$ & $6.19 \pm 0.61^{\mathrm{abc}}$ \\
\hline
\end{tabular}

${ }_{\mathrm{a}}^{\mathrm{a}}<0.05$ vs. sham group; ${ }_{\mathrm{p}}^{\mathrm{b}}<0.05$ vs. model of AMI group; ${ }^{\mathrm{c}} \mathrm{p}<0.05$ vs. preventive treatment group; ${ }^{\mathrm{d}} \mathrm{p}<0.05$ vs. COTG treatment group.

$(\mathrm{p}<0.05)$, which was higher than preventive treatment group and COTG treatment group $(\mathrm{p}<0.05)$ (Table 6).

\section{Discussion}

Cornus officinalis Sieb. et Zucc. was first recorded in the "Shen Nong's Herbal Classic", which is a tonic of traditional Chinese herbal drug, with the function of nourishing liver and kidney and astringent. According to modern pharmacological studies, chemical constituents of Cornus officenalis mainly include volatile components, glycosides (Cornus officinalis total glycosides, morroniside and loganin, etc.), polysaccharides, tannins, organic acids (malol, gallic acid, oleanolic acid, tartaric acid and malic acid, etc.) and other chemical composition [14] [15]. In recent years, research results have shown that Cornus officinalis extracts have great effect on anti-tumor [16] [17], anti-diabetic [18], lipid-lowering [19], anti-neurodegenerative disease [20], anti-osteoporosis [21], anti-aging [22] and improving sexual function [23] etc. Specifically, Cornus officinalis polysaccharide has comparatively conspicuous effects on antioxidant, cleaning effects on free radical [24]-[27] and promoting effects on humoral immunity, cellular immunity and nonspecific immunity of rats [28] [29]. Cornus officinalis glycosides, in addition, have anti-inflammatory effects [1] [30] [31]. In cardiovascular disease, the effective components of Cornus officinalis can attenuate myocardial ischemia reperfusion injury [1], lower blood pressure, reverse myocardial hypertrophy, improve cardiac function [2], protect blood vessel, regulate vascular function, stabilize the milieu interne [3], etc. The research result shows that COTG and CP can improve cardiac function of rats, prevent myocardial hypertrophy and reduce myocardial infarct size.

In cardiac myocyte, mitochondrial mass is $1 / 3$ of myocardial mass. Nevertheless, the content of mitochondria in tissues is not static, which can be synthesized to meet the needs of the body in a certain condition [28]. Ideally, the mitochondrial biogenesis is that enough normal mitochondria replace the damaged mitochondria to meet the needs of myocardial energy. Mitochondrial biogenesis program in heart can exhibit adaptive remodeling following biomechanical and oxidative stress, to protect myocardium metabolism [29]. The transcriptional coacti- 
Table 6. The Ct value of GSK-3 $\beta$ in myocardial tissue of five groups.

\begin{tabular}{cccccc}
\hline Group & $\begin{array}{c}\text { Sham } \\
(\mathrm{n}=12)\end{array}$ & $\begin{array}{c}\text { Model } \\
(\mathrm{n}=12)\end{array}$ & $\begin{array}{c}\text { Prevention } \\
(\mathrm{n}=12)\end{array}$ & $\begin{array}{c}\text { Cornus officinalis Total Glycosides } \\
(\mathrm{n}=12)\end{array}$ & $\begin{array}{c}\text { Cornus polysaccharides } \\
(\mathrm{n}=12)\end{array}$ \\
\hline GSK-3 $\beta$ & $6.90 \pm 0.83$ & $4.69 \pm 0.72^{\mathrm{a}}$ & $4.46 \pm 0.88^{\mathrm{a}}$ & $5.08 \pm 0.72$ & $5.98 \pm 0.42^{\mathrm{abcd}}$ \\
\hline
\end{tabular}

${ }^{a} \mathrm{p}<0.05$ vs. sham group; ${ }^{\mathrm{b}} \mathrm{p}<0.05$ vs. model of AMI group; ${ }^{\mathrm{c}} \mathrm{p}<0.05$ vs. preventive treatment group; ${ }^{\mathrm{d}} \mathrm{p}<0.05$ vs. COTG treatment group.

vator PGC-1, and especially PGC-1a and PGC-1 beta, are important regulation factors of mitochondrial biosynthesis and energy metabolism [30]-[33]. NRF-1 can turn on the mitochondrial TFA gene; in turn, mtTFA gene can activate gene which produces mitochondria [31]-[33].

Abnormalities in mitochondrial biogenesis can lead to cardiac dysfunction. It has been exhaustively demonstrated that mitochondrial biogenesis can make the heart easier to tolerate the injury caused by ischemia, whose principle mainly includes that mitochondrial biogenesis can improve cardiomyocyte energy metabolism and inhibit myocardial apoptosis [34]. Liu J. et al. [35] have demonstrated that attenuation of mitochondrial biogenesis and enhanced oxidative stress can lead to increased ischemic myocardial injury and impaired recovery of function after reperfusion. Some studies have shown that mitochondrial biogenesis impairment is an early event in the development of heart failure, boosting mitochondrial biogenesis to be beneficial for the treatment of heart failure [36] [37]. Therefore, abnormalities in mitochondrial biogenesis will aggravate the injury of myocardial infarction and eventually lead to heart failure. A number of studies clearly indicate that GSK-3 $\beta$ is closely correlated with myocardial protection, related to inhibition of apoptosis and protection of myocardial mitochondria [38] [39]. However, the study about effects of GSK-3 on mitochondria is rare.

Would the mitochondrial biogenesis become a therapeutic target for increasing myocardial tolerability to anoxic injury? Would Cornus officinalis Total Glycosides and Cornus polysaccharide improve myocardial ischemia injury by promoting mitochondrial biogenesis? Would preventive treatment reduce myocardial injury after myocardial infarction? The related research is very few. Our earlier studies have confirmed that the effective components of Cornus officinalis have protective effect on acute myocardial infarction in rat myocardium, improving cardiac function in rats and reducing myocardial infarct size, which might be achieved by effect of anti-oxidative damage and anti-inflammation. On the basis of this study, combined with the important role of mitochondria in cells, the aim of our study is to investigate the mechanism of Cornus officinalison myocardial protection. The study found that expression of related genes such as PGC- $1 \alpha$, PGC- $1 \beta$, NRF-1 mRNA in rat myocardial mitochondria decreased after acute myocardial infarction, and furthermore, myocardial ischemia hindered mitochondrial biogenesis, resulting in energy metabolism disorder of cardiomyocyte, which aggravated ischemic injury. Whether prevention or treatment administration, Cornus officinalis Total Glycosides and Polysaccharide can promote myocardial mitochondrial biogenesis, and the promoting effect of COTG prevention group is more significant than that of COTG treatment group and CP treatment group. It is further demonstrated that the myocardial cell had a beneficial change after treating with Cornus officinalis Total Glycosides and Polysaccharide. Specifically, quantity of mitochondria increased to improve myocardial cell energy metabolism, adapting ischemia and hemodynamic changes after myocardial infarction. However only preventive medication does not completely reverse the myocardial damage. This research indicates that Cornus officinalis Total Glycosides and Polysaccharide can reduce expression of GSK-3 $\beta$ mRNA to reduce myocardial injury. Their protective effects on the mitochondria of cadiocytes might be achieved by GSK-3 $\beta$ signal pathway, which has not been found in previous studies.

\section{Acknowledgements}

This work was supported by the State Administration of traditional Chinese Medicine of Guangdong Province (No. 20111165). We thank Professor Dongmei Sun for assistance in this study.

\section{References}

[1] Jiang, W.L., Zhang, S.M., Tang, X.X., et al. (2011) Protective Roles of Cornuside in Acute Myocardial Ischemia and Reperfusion Injury in Rats. Phytomedicine, 18, 266-271. http://dx.doi.org/10.1016/j.phymed.2010.07.009

[2] Fang, W.J., Feng, J.F., Lu, X.M., et al. (2012) Effect of Cornus officinalis Fruit Core Extract on the Cardiac Hyper- 
trophy Induced by Two Kidney Two Clip. Journal of Chinese Medicine Materials, 35, 1985-1989.

[3] Wu, J.L., Xu, H.Q., Shen, C.S., et al. (2013) Protective Effects of the Cornus officinalis Compatibility of Components on Cardiovascular Lesion in Diabetic Rats. Chinese Pharmacological Bulletin, 29, 382-386.

[4] Song, Z.F. (2013) Poly (ADP-Ribose) Polymerase Contributes Myocardial Ischemia-Reperfusion of Rats by Regulating Akt Signaling Pathway. Chinese Journal of Cardiology, 41, 156-160.

[5] Xu, Z., Lee, S. and Han, J. (2013) Dual Role of Cyclic GMP in Cardiac Cell Survival. International Journal of Biochemistry \& Cell Biology, 45, 1577-1584. http://dx.doi.org/10.1016/j.biocel.2013.04.027

[6] Dong, M., Hu, N., Hua, Y., et al. (2013) Chronic Aktactivation Attenuated Lipopolysaccharide-Induced Cardiac Dysfunction via Akt/GSK3 $\beta$-Dependent Inhibition of Apoptosis and ER Stress. Biochimica et Biophysica Acta, 1832, 848863. http://dx.doi.org/10.1016/j.bbadis.2013.02.023

[7] Choi, S.E., Jang, H.J., Kang, Y., et al. (2010) Atherosclerosis Induced by a High-Fat Diet Is Alleviated by Lithium Chloride via Reduction of VCAM Expression in ApoE-Deficient Mice. Vascular Pharmacology, 53, 264-272. http://dx.doi.org/10.1016/j.vph.2010.09.004

[8] van den Akker, F. and Deddens, J.C. (2013) Cardiac Stem Cell Therapy to Modulate Inflammation upon Myocardial Infarction. Biochimica et Biophysica Acta, 1830, 2449-2458. http://dx.doi.org/10.1016/j.bbagen.2012.08.026

[9] Wu, Y., Yin, X., Wijaya, C., et al. (2011) Acute Myocardial Infarction in Rats. Journal of Visualized Experiments, 48, e2464. http://dx.doi.org/10.3791/2464

[10] Wu, H., Liang, H., Liu Y.H., et al. (2003) Extraction and Determination of Total Saponins from Cornus officinalis Sieb. et Zucc. Journal of the Fourth Military Medical University, 24, 430-432.

[11] Zhang, C.Y., Zhang, L., Hui, F.L., et al. (2007) Extraction and Determination of the Content of Polysaccharide from Fructus Corni. Lishizhen Medicine and Materia Medica Research, 18, 313-314.

[12] Wang, X.Q., Hu, C.H., Wu, G.F., et al. (2007) Study on Decreasing Mortality of Rat Model with Myocardial Infarction. South China Journal of Cardiovascular Diseases, 13, 141-144.

[13] Lei, J., Wu, W., Xue, Z.N., et al. (2009) Establishment and Assessment of a Rat Experimental Model of Acute Myocardial Infarction. China Practical Medical, 4, 1-3.

[14] Li, Y.K., et al. (2006) Pharmacological Experimental Methodology of Traditional Chinese Medicine. 2nd Edition, Shanghai Science and Technology Press, Shanghai, 38-39, 51.

[15] Liao, C.L., Lin, J.H., Lien, J.C., et al. (2015) The Crude Extract of Fructus Corni Inhibits the Migration and Invasion of U-2 OS Human Osteosarcoma Cells through the Inhibition of Matrix Metalloproteinase-2\#9 by MAPK Signaling. Environmental Toxicology, 30, 53-63. http://dx.doi.org/10.1002/tox.21894

[16] Liao, C.L., Hsu, S.C., Yu, C.C., et al. (2014) The Crude Extract of Corni fructus Induces Apoptotic Cell Death through Reactive Oxygen Species-Modulated Pathways in U-2 OS Human Osteosarcoma Cells. Environmental Toxicology, 29, 1020-1031. http://dx.doi.org/10.1002/tox.21832

[17] Park, C.H., Noh, J.S., Tanaka, T., Uebaba, K., Cho, E.J. and Yokozawa, T. (2011) The Effects of Corni fructus Extract and Its Fractions against $\alpha$-Glucosidase Inhibitory Activities in Vitro and Sucrose Tolerance in Normal Rats. The American Journal of Chinese Medicine, 39, 367-380. http://dx.doi.org/10.1142/S0192415X11008889

[18] Hwang, J.H. and Kim, J.D. (2011) Inhibitory Effects of Corni fructus Extract on Angiogenesis and Adipogenesis. The Korean Journal of Physiology and Pharmacology, 15, 43-51.

[19] Hong, S.Y., Jeong, W.S. and Jun, M. (2012) Protective Effects of the Key Compounds Isolated from Corni fructus against $\beta$-Amyloid-Induced Neurotoxicity in PC12 Cells. Molecules, 17, 10831-10845. http://dx.doi.org/10.3390/molecules170910831

[20] Sun, H., Li, L., Zhang, A., et al. (2013) Protective Effects of Sweroside on Human MG-63 Cells and Rat Osteoblasts. Fitoterapia, 84, 174-179. http://dx.doi.org/10.1016/j.fitote.2012.11.010

[21] Wu, Y.F., Wang, X.S., Shen, B., Kang, L. and Fan, E.G. (2013) Extraction, Structure and Bioactivities of the Polysaccharides from Corni fructus. Recent Patents on Food, Nutrition \& Agriculture, 5, 57-61. http://dx.doi.org/10.2174/2212798411305010009

[22] Celep, E., Aydin, A., Kirmizibekmez, H. and Yesilada, E. (2013) Appraisal of in Vitro and in Vivo Antioxidant Activity Potential of Cornelian Cherry Leaves. Food and Chemical Toxicology, 62, 448-455. http://dx.doi.org/10.1016/j.fct.2013.09.001

[23] Jiang, Z.Q., Li, Y. and Jiang, L.H. (2013) Hepatoprotective Effects of Extracts from Processed Corni fructus against D-Galactose-Induced Liver Injury in Mice. Journal of Chinese Medicinal Materials, 36, 85-89.

[24] Du, W.F., Wang, M.Y. and Cai, B.C. (2008) Effect of Polysaccharides in Crude and Processed Cornus officinalis on the Immunologic Function of Mice with Immunosuppression Induced. Journal of Chinese Medicinal Materials, 31, 715-717. 
[25] Zou, P.W., Zhao, Z.J., Li, P. and Huang, H. (2012) Study on the Anti-Tumor Effect of Polysaccharides from Cornus officinalis and Its Immunologic Mechanism. Chinese Journal of Hospital Pharmacy, 32, 20-22.

[26] Yamabe, N., Noh, J.S., Park, C.H., et al. (2010) Evaluation of Ioganin, Iridoid Glycoside from Corni fructus, on Hepatic and Renal Glucolipotoxicity and Inflammation in Type 2 Diabetic db/db Mice. European Journal of Pharmacology, 648, 179-187.

[27] Yokozawa, T., Kang, K.S., Park, C.H., et al. (2010) Bioactive Constituents of Corni fructus. The Therapeutic Use of Morroniside, Ioganin, and 7-O-galloyl-D-sedoheptulose as Renoprotective Agents in Type 2 Diabetes. Drug Discoveries \& Therapeutics, 4, 223-234.

[28] Carreira, R.S., Lee, P. and Gottlieb, R.A. (2011) Mitochondrial Therapeutics for Cardioprotection. Current Pharmaceutical Design, 17, 2017-2035. http://dx.doi.org/10.2174/138161211796904777

[29] Xiao, J., Chert, L., Wang, X.F., Liu, M. and Xiao, Y.B. (2012) ENOS Correlates with Mitochondrial Biogenesis in Hearts of Congenital Heart Disease with Cyanosis. Arquivos Brasileiros de Cardiologia, 99, 780-788. http://dx.doi.org/10.1590/S0066-782X2012005000072

[30] Leone, T.C. and Kelly, D.P. (2011) Transcriptional Control of Cardiac Fuel Metabolism and Mitochondrial Function. Cold Spring Harbor Symposia on Quantitative Biology, 76, 175-182. http://dx.doi.org/10.1101/sqb.2011.76.011965

[31] Scarpulla, R.C. (2011) Metabolic Control of Mitochondrial Biogenesis through the PGC-1 Family Regulatory Network. Biochimica et Biophysica Acta (BBA)—Molecular Cell Research, 1813, 1269-1278. http://dx.doi.org/10.1016/j.bbamcr.2010.09.019

[32] Scarpulla, R.C. (2008) Nuclear Control of Respiratory Chain Expression by Nuclear Respiratory Factors and PGC-1Related Coactivator. Annals of the New York Academy of Sciences, 1147, 321-334. http://dx.doi.org/10.1196/annals.1427.006

[33] Gaziev, A.I. and Shaǐkhaev, G.O. (2008) Lesions of the Mitochondrial Genome and Ways of Its Preservation. Genetika, 44, 437-455.

[34] Sun, L., Zhao, M., Yu, X.J., et al. (2013) Cardioprotection by Acetylcholine: A Novel Mechanism via Mitochondrial Biogenesis and Function Involving the PGC-1 $\alpha$ Pathway. Journal of Cellular Physiology, 228, 1238-1248. http://dx.doi.org/10.1002/jcp.24277

[35] McLeod, C.J., Pagel, I. and Sack, M.N. (2005) The Mitochondria Biogenesis Regulatory Program in Cardiac Adaptation to Ischemia-A Putative Target for Therapeutic Intervention. Trends in Cardiovascular Medicine, 15, 118-123. http://dx.doi.org/10.1016/j.tcm.2005.05.001

[36] Liu, J. and Lloyd, S.G. (2013) High-Fat, Low-Carbohydrate Diet Alters Myocardial Oxidative Stress and Impairs Recovery of Cardiac Function after Ischemia and Reperfusion in Obese Rats. Nutrition Research, 33, 311-321. http://dx.doi.org/10.1016/j.nutres.2013.02.005

[37] Yan, W., Zhang, H., Liu, P., et al. (2013) Impaired Mitochondrial Biogenesis Due to Dysfunctional AdiponectinAMPK-PGC-1 $\alpha$ Signaling Contributing to Increased Vulnerability in Diabetic Heart. Basic Research in Cardiology, 108, 329. http://dx.doi.org/10.1007/s00395-013-0329-1

[38] Bayeva, M., Gheorghiade, M. and Ardehali, H. (2013) Mitochondria as a Therapeutic Target in Heart Failure. Journal of the American College of Cardiology, 61, 599-610. http://dx.doi.org/10.1016/j.jacc.2012.08.1021

[39] Jirkovsky, E., Popelova, O., Krivakova-Stankova, P., et al. (2012) Chronic Anthracycline Cardiotoxicity: Molecular and Functional Analysis with Focus on Nuclear Factor Erythroid 2-Related Factor 2 and Mitochondrial Biogenesis Pathways. The Journal of Pharmacology and Experimental Therapeutics, 343, 468-478. http://dx.doi.org/10.1124/jpet.112.198358 